\title{
Erratum to: Unexpectedly high outcrossing rate in both dense and sparse patches in self-compatible Pedicularis rex (Orobanchaceae)
}

\author{
Jing Xia $\cdot$ Hong Liu $\cdot$ Rui Qin
}

Published online: 21 November 2012

(C) Springer-Verlag Wien 2012

\section{Erratum to: Plant Syst Evol}

\section{DOI 10.1007/s00606-012-0701-x}

Due to an unfortunate error, the names of all authors have been published in the incorrect order both in the author list and affiliation of the original publication. The corrected author list is given below:

Jing Xia $\cdot$ Hong Liu $\cdot$ Rui Qin

The online version of the original article can be found under doi:10.1007/s00606-012-0701-x. 